\title{
Researching shadow education: methodological challenges and directions
}

\author{
Mark Bray
}

Received: 20 June 2009/Revised: 30 September 2009/Accepted: 15 November 2009/Published online: 28 January 2010

(c) Education Research Institute, Seoul National University, Seoul, Korea 2010

\begin{abstract}
Research on shadow education has considerably increased in volume and has helped to improve understanding of the scale, nature, and implications of the phenomenon. However, the field is still in its infancy. Literature on shadow education reflects confusion over terms and parameters, and data suffer from challenges in securing evidence from actors who may be unwilling or unable to respond to enquiries in a clear manner. Particular care is needed in cross-national and cross-cultural comparisons. Nevertheless, the trajectory of improvement in both conceptualisation and instrumentation gives ground for confidence that shadow education will be progressively better documented and better understood.
\end{abstract}

Keywords Shadow education - Private tutoring ·

Research methods - Comparative education

Shadow education has become much more visible worldwide during the last decade. This increased visibility seems to reflect two forces. First, the shadow appears to have expanded and become denser; and second, the shadow has been better documented (Lee et al. 2009). Some of this documentation has been undertaken by researchers in universities and comparable bodies, while other documentation has been provided by governments, international agencies, journalists, and others. However, the basis of evidence about shadow education has many shortcomings. Data from some parts of the world are more robust than from others, and

\section{Bray $(\bowtie)$}

Comparative Education Research Centre, Faculty of Education,

The University of Hong Kong, Pokfulam Road, Hong Kong,

China

e-mail: mbray@hku.hk fundamental difficulties may arise in attempts to make cross-national and cross-cultural comparisons.

This paper to some extent reflects the author's personal experience in collecting empirical data and assembling profiles on the basis of other people's data. These efforts have involved both quantitative and qualitative work. During the 1990s, the author prepared a book on shadow education for UNESCO's International Institute for Educational Planning (IIEP). This book (Bray 1999a) sketched a global picture with the goal of identifying patterns, trends, and implications for educational planners. The experience of preparing the book was intellectually exciting since it ventured into new conceptual ground. However, because the evidence base was very sketchy, the task was somewhat like assembly of a jigsaw puzzle with most of the pieces missing. A decade later, more pieces in the puzzle are available. However, many gaps remain, not only in certain parts of the world but also in specific subthemes. A major question, therefore, is how the evidence base can be improved.

\section{Defining the focus of investigation}

The first challenge for researchers in this domain is to define the focus of investigation. Almost axiomatically a sector which is shadowy is indistinct, and the literature on this theme employs a range of definitions and therefore encounters problems of comparability.

In the research literature, the term shadow education dates from the early 1990s. An investigation of out-ofschool private tutoring had been sponsored by the Singapore office of Canada's International Development Research Centre (IDRC) and generated detailed studies in Sri Lanka (de Silva et al. 1991) and Malaysia (Marimuthu et al. 1991). The latter commenced by observing (p. vi) that: 
The study ... found that a considerable percentage of youths attended private tuition [as private tutoring was more commonly called in Malaysia] in order to prepare themselves for the selective national examinations. Experience ... showed that the practice of private tuition was so prevalent that it could be considered as a "shadow educational system".

The following year, Stevenson and Baker (1992) independently used the metaphor in the title of an article about Japan; and in parallel the metaphor was used in Singapore by George (1992).

These authors used the metaphor in slightly different ways. Marimuthu et al. (1991) did not explicitly define what they meant by shadow educational systems, but were in effect describing the way that supplementary tutoring mimicked the mainstream, growing as the mainstream grew and changing shape as the mainstream changed shape. They noted that private tutoring existed at primary and secondary levels, and focused their empirical work on the latter. George (1992) had a similar conception and presented Singaporean data from both primary and secondary levels. Stevenson and Baker had a slightly wider focus. They defined shadow education (p. 1639) as "a set of educational activities that occur outside formal schooling and are designed to enhance the student's formal school career" and added that they were concerned about two sets of activities. One set occurred mainly during the period of secondary schooling in private cram schools, correspondence courses and individual tutorial sessions, and the other set occurred immediately after secondary schooling in institutions known as yobiko which prepared students intensively to resit university entrance examinations. Stevenson and Baker added (p. 1643) that their conception of shadow education comprised "activities that are firmly rooted within the private sector".

Following these and other studies, the present author's 1999 book focused on extra tutoring for pupils who were still registered in primary and secondary schools rather than in yobiko-type institutions for students who had already left school. More specifically, the parameters of that book were defined (Bray 1999a, p. 20) by:

- supplementation: tutoring that addressed subjects already covered in school and excluding, for example, language classes for minority children whose families were anxious that new generations retained competence in languages not taught in mainstream schools;

- privateness: tutoring provided in exchange for a fee, as opposed to unpaid tutoring provided by families or community members, or extra tutoring provided by teachers as part of their professional commitments and responsibilities;
- academic subjects, particularly languages, mathematics, and other examinable subjects, and excluding musical, artistic or sporting skills which are learned primarily for pleasure and/or for a more rounded form of personal development.

Of course the definition utilised for research depends on the task at hand, and in turn shapes the focus. The present author's interest in private tutoring grew out of concern about costs of schooling and, in particular, the economic burden on poor households. Work in East Asia commissioned by UNICEF and the World Bank showed that substantial costs for tutoring were being incurred by some households (Bray 1996, pp. 14-17), and these costs were ignored or hidden by analyses which addressed only government expenditures. For this work, therefore, the main focus was on the costs of tutoring per child at different levels of education, which could then be analysed in the context of household budgets. Other researchers have been more interested in the educational impact of tutoring and have therefore sought to measure cognitive achievement (e.g. Baker et al. 2001; Mischo and Haag 2002). Yet other researchers have focused on such themes as social stratification, marketing strategies, teachers' lives, and technology (e.g. Buchmann 2002; Davies and Aurini 2006; Popa and Acedo 2006; Ventura 2008a).

The question whether, and in what circumstances, the term shadow education embraces unremunerated work in addition to fee-paying work is of considerable importance. To illustrate this point, it is useful to refer to the Third International Mathematics and Science Study (TIMSS) and its successor Trends in International Mathematics and Science Study (also called TIMSS), and to the Southern and Eastern Africa Consortium for Monitoring Educational Quality (SACMEQ).

The TIMSS research is operated under the umbrella of the International Association for the Evaluation of Educational Achievement (IEA). The first TIMSS tests in 1995 collected data on learning of mathematics and science in five grades in 45 countries (Martin 1996, pp. 1-2). The second round was conducted in 1999 and focused on Grade 8 in 38 countries (Robitaille and Beaton 2002, p. 11); the third round in 2003 collected data from Grades 4 and 8 in 49 countries (Mullis et al. 2005); and the fourth round collected comparable data from the same grades in 59 countries (Mullis and Martin 2008). For the mathematics component of the 1995 survey, students in Grades 7 and 8 were asked: "During the week, how much time before or after school do you usually spend taking extra lessons/ cramming school in mathematics?" (TIMSS (Third International Mathematics and Science Study) 1998, pp. SQ 2-3). A similar question focused on science. Baker et al. (2001, p. 5) have asserted that: 
Close translations of this question from the original nation-specific questionnaires in Chinese, Japanese, and Spanish were conducted, and the closely translated meaning of the item was found to capture the full meaning of shadow education in each national system and each country's language.

But in fact the "full meaning of shadow education" was not captured even in English: the responses could—and it is clear from the patterns that many of them did-include extra coaching by teachers on an unremunerated basis as part of their normal workloads. This broad focus may have been acceptable to the architects of the TIMSS project, but it was problematic to analysts interested in shadow education. If shadow education is defined as "activities that are firmly rooted within the private sector" (see above-Stevenson and Baker 1992, p. 1643), then the data were evidently contaminated.

A different problem with the question was the focus on extra lessons "during the week". Shadow education tends to vary in intensity during the year according to time availability (e.g. during school vacations) and examination pressures, and the question failed to capture major seasonal variations. For the 2003 survey, the question for Grade 8 students was refined to: "During this school year, how often have you had extra lessons or tutoring that is not part of your regular class in the following subjects" (TIMSS (Trends in International Mathematics and Science Study) 2003, p. 27). Respondents were then asked for information on mathematics, biology, earth science, chemistry and physics, with choices of "Every or almost every day", "Once or twice a week", "Sometimes", and "Never or almost never". Focus on the whole school year reduced the problem of seasonal variations, but did not eliminate it because the respondents would have had to make an average across high-peak and low-peak seasons, and the question still could not separate fee-free from fee-paying tutoring. Perhaps because these data were considered unsatisfactory, the 2007 TIMSS survey dropped the question about extra lessons altogether.

Similar challenges affected the SACMEQ data. In 1995, SACMEQ collected data on learning by Grade 6 pupils in seven education systems, and in 2000, SACMEQ collected related data in 14 education systems. Paviot et al. (2008) presented data on extra lessons in six countries which were common to both SACMEQ I and SACMEQ II. The 1995 survey did not ask whether the extra lessons were paid for. This question was asked in 2000, but the data did not seem conclusive because a very high percentage of the pupils responded that they "did not know" (Paviot et al. 2008, p. 151). As a result, researchers who define shadow education as covering only fee-paying instruction found that the data were less clear than they would have desired.
Identification of the focus of investigation may also require clarity in institutional conceptualisation. For example, Japan is well known for its juku, a term which is translated by Wolf $(2002$, p. 339) as "the Japanese institution that provides extra-school instruction" and by many other commentators (e.g. Refsing 1992, p. 126; Smith 2003, p. 576) simply as "cram school". However, close analysis of institutions which can be classified as juku reveals a huge range of types. Roesgaard (2006, p. 32) began with a broad distinction between academic gakush $\hat{u}$ juku and those directed towards arts, technical training, English conversation, etc. Then are distinctions among gakush $\hat{u} j u k u$ according to specialisations. Hosh $\hat{u}$ juku offer remedial teaching, while fukushî juku provide supplementary teaching, and yosh $\hat{u}$ juku provide preparatory teaching. Shingaku juku cater for pupils with high achievement who wish to do better, while kyôsai juku have a flexible approach in contrast to doriru juku which rely on drills and competitive exercises. Some operate under the category deai no ba or idokoro (a place to be and meet with friends), or even takujijo (care centre). Roesgaard went further to construct a typology based on atmosphere, focus of courses, relationship with the mainstream schooling system, the nature of the students, the teaching materials, size, admissions policies, and advertising strategies. Such classification thus shows the danger of superficial description of $j u k u$ as if they were basically a single type of institution.

Additional complexity arises from the fact that some tutoring in Japan is provided outside an institutional framework. Much one-to-one tutoring, in particular, is provided through informal channels in the tutors' or the pupils' homes. Other tutoring is provided through correspondence courses and, increasingly, via the internet. Thus, even a survey of $j u k u$ attendance that covered the broad institutional range would capture only part of the shadow education system. Similar remarks would apply in other countries.

Further factors concern the specific interests of the researcher. No study can cover every dimension of a phenomenon, and researchers must therefore choose particular elements. Roesgaard's list indicates the main dimensions in which she was interested, namely the general atmosphere, curriculum, admissions policies, advertising, etc. Other researchers might be more interested in the teachers than the students, or perhaps the nature of the premises, or mechanisms for regulation and control. At least in principle, the list of possible themes for investigation of shadow education could be as long as the list for regular education.

\section{Securing the data}

Even when the focus has been defined with clarity, reliable data may be very difficult to secure. One challenge 
concerns the ability and willingness of potential respondents to provide data, and another concerns the instruments for securing those data.

\section{Ability and willingness to provide data}

For most studies of shadow education, three main potential sources of data present themselves: the pupils receiving the lessons, the parents or other family members, and the persons providing the lessons (i.e. the tutors and perhaps their employers). However, these respondents may not possess the information sought, or in certain circumstances may be unwilling to reveal it.

An important factor when seeking information from pupils concerns their ages. This was evident to the present author when investigating the household costs of tutoring of primary school pupils in Cambodia (Bray 1999b). Some children had some idea of the costs since they themselves presented cash to the tutors, but, as might be expected, the younger the pupil the less likely it was that an accurate estimate of the cost could be provided. Turning to the households to find out the cost, the first challenge was to find out who in the households knew the answer. Mothers seemed more likely than fathers to take charge of this dimension, but in some households it was another family member; and even when an appropriate person had been found, the question would arise about the time period to be considered. Tutoring expenses, like tutoring activity, are commonly seasonal. Respondents may know how much they have paid recently, but could find it more difficult to make an annual estimate. Finally, even the tutors may not know the extent of the financial cost of tutoring. Even if they collect the fees themselves (and many do not, since they might be employed by a company or other organisation), they may do so only for the subjects in which they provide tutoring rather than all the subjects taken by a particular pupil.

Turning from ability to willingness to provide information, responses are naturally shaped by the respondents' understanding of why the researcher might be seeking the information. For cultural and other reasons, pupils may be unwilling to indicate even the number of hours per week during which they receive tutoring. For some pupils, tutoring might be associated with low academic performance and therefore bring elements of shame; and for other pupils, tutoring might be associated with high academic performance and could be seen as bringing an unfair advantage. Similar attitudes might apply to parents, who might not wish to expose themselves to external judgements on why they do or do not solicit tutoring for their children. And in some settings the tutors may be unwilling to provide information because they are collecting informal payments which are of doubtful legality and which perhaps should be taxed. Tutors may also hesitate to provide information on qualifications, premises, curricula, teaching methods, etc. Dindyal and Besoondyal (2007, p. 8) encountered such problems in Mauritius. Their survey of the views of 20 teachers, 28 students and five parents was "a convenience sample as many of them were not willing to talk about private tuition openly". The problem would be recognised by counterpart researchers in other countries.

To balance this picture are other circumstances in which respondents are very willing to provide data. When collecting data from pupils in classrooms, much depends on the climate of trust. The present author has collected data from pupils via their classroom teachers who have been part-time students on in-service courses taught by the author. These teachers have had sufficient trust in the author and in turn have had sufficient trust from their pupils. Limitations may still have remained in what the pupils actually knew and in the comprehensiveness of the questions, but at least the barrier of willingness was reduced. Similar approaches may be made to parents through Parent-Teacher Associations, community bodies, etc. And some tutoring companies are very responsive because they see the data that they provide as a form of advertising. This, however, presents different demands for care in interpretation. One would expect the companies only to release the data which those companies feel portrays them in a favourable light.

The approach in a study of nine countries in Eastern Europe and Central Asia sponsored by the Open Society Institute (OSI) is also worth noting (Silova et al. 2006). The researchers targeted first-year university students on the assumption that they would be sufficiently forthright about their experiences of private tutoring when in secondary school. Having just entered the universities, it was argued, first-year students would have fresh memories about the last year of their secondary schooling and would have little reason to hide information. However, the university sample did not represent all students who had left secondary school and was biased towards relatively high academic achievers. To gain information on a wider population, the respondents were asked to estimate the scope of tutoring among their classmates. Researchers in three of the nine countries conducted an additional survey of secondary school students to expand the respondents' pool and secure some triangulation.

Instruments for collecting data

Even when respondents are able and willing to provide data, the ultimate quality of the data collected will only be as good as the instruments. In this connection, insights can be gained from both quantitative and qualitative research.

The literature contains reports of various quantitative surveys. Some exclusively focus on shadow education (e.g. 
Marimuthu et al. 1991; Silova et al. 2006). Others are broadly focused in the education sector and contain questions about private tutoring alongside questions about other matters. International examples include the TIMSS and SACMEQ surveys noted above, and national examples include data collected by the Turkish Higher Education Council (Gurun and Millimet 2008) and the School Leavers' Surveys administered in Ireland (Smyth 2009). Data on tutoring may also be collected from wider enquiries such as the Egyptian Labor Market Survey (Elbadawy et al. 2006) and the Vietnam Living Standards Measurement Survey (Dang 2007).

In addition to the usual challenges of sampling, securing adequate responses, coding and processing, surveys which have asked about shadow education have encountered major challenges in asking questions that are both sufficiently precise and easily understood by the respondents. Some of these challenges have been alluded to above in connection with TIMSS and SACMEQ and can be further illustrated by the Programme for International Student Assessment (PISA) of the Organisation for Economic Co-operation and Development (OECD). PISA has tested learning achievements of 15 -year olds in multiple education systems (43 in 2000, 41 in 2003, and 58 in 2006). The 2006 parent questionnaire requested data on total family education spending, but did not differentiate expenditures on tutoring from those on other items (Organisation for Economic Co-operation and Development (OECD) 2005a); and the student questionnaire requested data on out-ofschool-time lessons, but did not differentiate lessons by private tutors from other lessons (Organisation for Economic Co-operation and Development (OECD) 2005b).

Elaborating, the 2006 PISA questionnaire for students contained 37 questions of which two focused on shadow education. Question 31, of which the stem and first part (for science) are reproduced in Fig. 1, gave five choices for outof-school-time lessons typically received per week, and in addition to science had separate sections for mathematics, languages, and "other subjects". Respondents would have had to decide what sort of week could be described as typical, and, as with the TIMSS questions, the responses might have failed to allow for seasonal variations.

Question 32 then asked who provided the out-of-schooltime lessons (Fig. 2). With its six subquestions, this was already quite demanding as a proportion of the questionnaire, and, like all such surveys, resulted from judgement by the researchers on what would be both useful and a priority to ask. Scope was provided to change the terms $<$ One to one $>$ and $<$ teacher $>$ to fit preferred vocabulary such as $<$ Individualised $>$ and $<$ tutor $>$. The focus was on the identity of the teacher and the duration of the lessons that the students received currently. It is possible that "currently" was interpreted differently from "typically" in Question 31. No questions were asked about location, motivation, costs, the nature of learning, or multiple other aspects that many analysts of shadow education would like to have learned about. The chief merit of the survey was that it provided comparable data across 58 education systems. However, the responses from the Japanese respondents, for example, would not easily be mapped against the
Fig. 1 Part of Question 31 in the 2006 PISA Student Questionnaire

\section{Q31 How much time do you typically spend per week studying the following subjects?}

For each subject, please indicate separately:

- the time spent attending regular lessons at your school;

- the time spent attending out-of-school-time lessons rat school, at home or somewhere else);

- the time spent studring or doing homework by yourself.

$<$ An hour here refers to 60 minutes, not to a class period>

(Please tick only one box in each row)

\section{<School science>}

a) Regular lessons in $<$ school science at my school

b) Out-of school-time lessons in school science

c) Study or homework in $\mathrm{school}$ science by myself

\begin{tabular}{|c|c|c|c|}
\hline $\begin{array}{c}\text { Less } \\
\text { than } 2 \\
\text { hours a } \\
\text { week }\end{array}$ & $\begin{array}{l}\text { 2or } \\
\text { more but } \\
\text { less than } \\
\text { t hours } \\
\text { a week }\end{array}$ & $\begin{array}{l}\text { tor } \\
\text { more but } \\
\text { less than } \\
6 \text { hours } \\
\text { a week }\end{array}$ & $\begin{array}{c}6 \text { or } \\
\text { more } \\
\text { hours a } \\
\text { reeek }\end{array}$ \\
\hline$\square$ & $\square$; & $\square_{4}$ & $\square_{5}$ \\
\hline$\square_{2}$ & $\square_{3}$ & $\square_{4}$ & $\square_{5}$ \\
\hline & $\square_{3}$ & $\square_{4}$ & $\square_{5}$ \\
\hline
\end{tabular}


Fig. 2 Question 32 in the 2006 PISA Student Questionnaire

\section{Q32 What type of out-of-school-time lessons do you attend currently (if any)?}

These are lessons in subjects that you are learning at school, that you spend extra time learning outside of normal school hours. The lessons might be held at your school, at your home or somewhere else. These are only lessons in subjects that you also learn at school.

(Please tick only one box in each row)

a) One to one lessons with a teacher who is also a teacher at your school

b) One to one lessons with a teacher who is not a teacher at your school

c) Lessons in small groups (less than 8 students) with a teachers who is also a teacher at vour school

d) Lessons in small groups (less than 8 students) with a teacher who is not a teacher at your school

e) Lessons in larger groups ( 8 students or more) with a teacher who is also a teacher at your school

f) Lessons in larger groups ( 8 students or more) with a teacher who is not a teacher at your school

Yes No
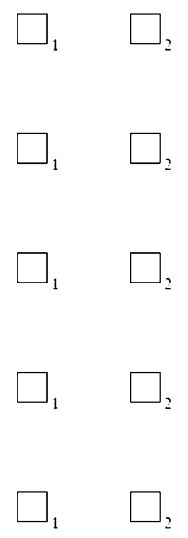

many types of juku identified by Roesgaard (2006) to provide analyses of the dynamics of shadow education in that country.

If the scope for specific questions on tutoring seems constrained in this type of questionnaire, it is usually even more constrained in questionnaires that focus on broader matters in household surveys. Such investigations have to cater for a wide range of purposes, and thus it may already be an achievement to secure a single question on shadow education which can then be mapped against households of particular types and in particular locations. Dang (2007) remarked on the value of data from the Vietnam Living Standards Survey but added that it only asked for expenditure on private tutoring for each student without specifying the type of classes. As a result, Dang observed (p. 686), "it may not be possible to exactly separate ... private tutoring in academic subjects taught and tested at mainstream schools compared to that of private tutoring in subjects not taught (and tested) at school, which may be pursued simply for entertainment or further human development such as fine arts or martial arts".

From a methodological viewpoint, two studies in England commissioned by the government's Department for Children, Schools and Families (DCSF) are also worth noting. One focused on agencies providing tutoring in the marketplace (Tanner et al. 2009). The researchers identified
504 agencies from review of websites, from which 300 were invited to take part in a telephone survey to augment the findings of the database analysis. Structured interviews with 130 agencies focused on the characteristics of the agencies and tutors, arrangements for tutorials, and costs. A further 17 in-depth interviews were conducted with tutors in selected towns. The study could not answer every type of query, but was the first of its kind in England and significantly advanced knowledge of the sector.

The second study published in the same year (Peters et al. 2009) was a spin-off from a telephone survey on the costs of schooling. A total of 1,500 parents and carers were interviewed using random-digit dialling and screening questions to select a sample of people with children aged 5-16 in state education. Interviewers checked that the respondent was the best able to talk about the child's education, and if there was more than one child aged 5-16 in state school in the household, one was selected at random using the most-recent-birthday rule. The survey secured data on the prevalence of private tutoring, the most popular subjects, type, frequency and duration of tutoring, and correlations with household income. The researchers claimed (p. 2) that the achieved sample was representative of the population in question on a range of measures.

Alongside such surveys are more modest ones conducted by individual researchers without the assets of large 
teams and substantial funding. Many of these studies are qualitative rather than quantitative. An example is Hartmann's (2008) study of tutoring in Egypt which uses methods from the field of urban anthropology, i.e. participant observation, semi-structured interviews, and informal conversations. The resulting report achieved insights which could never have been secured through quantitative approaches. Perhaps more than most forms of research, the researcher herself-and her personality, reflections and interpretations-was one of the most important instruments for the research. Hartmann described at length the ways in which she built relationships and the various cautions that should be taken into account in the interpretation of data.

Related studies were conducted in Egypt by Megahed and Ginsburg (2003) and in Romania by Popa and Acedo (2006). Megahed and Ginsburg interviewed 12 teachers in Cairo who had between five and 20 years of experience, to gain their perspectives on educational reform. Their views on supplementary tutoring were covered under the heading of ideologies of professionalism. The researchers presented quotations from interview transcripts, and highlighted, among various dimensions, gender differences in perceptions. The paper by Popa and Acedo was based on participant observation and in-depth and semi-structured interviews with 16 teachers in four high schools. These researchers did not find differences between male and female teachers' perceptions of tutoring, but did also link tutoring to ideologies of professionalism.

Other data may be more superficial but still useful. Journalists, for example, commonly highlight the experiences and perspectives of individual children and/or tutors (see e.g. George 1992; Mulji 2003; Choe 2009; Ng 2009). As sources of data, most of these accounts could be described as vignettes more than sophisticated analyses; but vignettes can also assist with understanding of the phenomenon. Moreover, some journalistic investigations are thorough and extensive. An example is a television documentary in France which interviewed parents and tutorial agencies, and which filmed a number of private tutorial lessons (Bendall and Tourte 2009).

\section{Interpreting the data}

Once data have been secured-from any source, and through any method-the analyst of course has to interpret them. In one respect, this task is little different in the domain of shadow education from the domain of regular education. However, particular challenges arise in shadow education, first because conceptualisation is in its infancy, second because data gaps remain very evident, and third because the field is undergoing rapid change. The speed of change partly reflects the entrepreneurialism of shadow education providers, many of whom harness technologies which are themselves evolving at great speed. Additional factors reflect social and economic changes associated with geopolitical and other forces. With this in mind, this section of the paper remarks on some interpretations of the data in the light of ways in which the data have been collected. Despite the methodological limitations, clearly a great deal of analysis is possible. Particular attention is here given to cross-national and cross-cultural comparisons.

Much of the literature to which this paper has referred is inherently international, while other studies have been conceived as national or local endeavours but can also be instructively compared across national boundaries. Some of the strengths and challenges of cross-national comparisons of shadow education deserve elaboration. The field of comparative education pays considerable attention to units of analysis (see e.g. Noah and Eckstein 1998; Crossley and Watson 2003; Bray et al. 2007). The literature on shadow education focuses on many units, including individuals, classrooms, schools, provinces, whole education systems, and world regions. Expanding on two extremes, at the individual level some researchers have considered the motivations and modes of operation of pupils and teachers (e.g. Kim 2007; Hartmann 2008); while at the level of world regions, researchers have focused on East Asia (Kwok 2004), Europe (Ventura 2008b), Africa (Bray and Suso 2008), and Central Asia (Silova 2009). When analyses take multiple levels, it is easier to see how patterns may be nested within each other, i.e. the actions of individual pupils may be influenced by the cultures of their classrooms, which in turn are influenced by the cultures of their schools, which in turn are influenced by the cultures of their communities, districts, countries, and world regions (Manzon 2007; Mason 2007).

Reversing the flow of analysis, one reason why tutoring at the individual and school level is very different in, say, Cambodia and Singapore, is that the cultures and economic structures of those two countries are very different. Cambodia is a less-developed country in which teachers have low levels of professional development and in which supplementary tutoring has become a common way for regular teachers to supplement their incomes in order to secure a reasonable standard of living. In Cambodia, as in other low-income countries such as Azerbaijan and Bangladesh, it has become acceptable for teachers to demand payment for extra tutoring of pupils for whom those teachers already have responsibility in mainstream classes. This can raise major challenges, including the possibility of a form of blackmail in which teachers withhold parts of their regular lessons in order to increase the market for private tutoring (Bray 1999b, p. 61; Dawson 2009, p. 65). In Singapore, teachers are well remunerated, are more closely supervised, 
and have much higher standards of professionalism. Teachers are forbidden to tutor pupils from the schools in which those teachers are already employed. Tutoring is still common in Singapore (Tan 2009), but the providers of tutoring and the nature of the tutoring differ considerably from the dominant form in Cambodia. Singapore has many more commercial agencies which specialise in tutoring and also uses the internet and other technologies to a much greater extent than in Cambodia.

Taking this analysis further to consider wider cultural norms and economic structures helps to explain why private tutoring is vigorous in some countries and cultures but barely evident in others. Singapore, alongside mainland China, Hong Kong, Taiwan, Korea, and Japan, is dominated by Confucian cultures that value learning, effort, and certain types of competition (Rohlen and LeTendre 1996, p. 374; Salili 2005, p. 92). Rao and Chan (2009, p. 16) stress that this theme is complex and in constant change; but cultural factors certainly help to explain why patterns in East Asia have been different from those in Scandinavia, for example. Patterns in Eastern Europe resemble those in Cambodia more closely because they reflect the severe strains on state structures in the early 1990s following the collapse of socialism. Teachers who remained in government schools were forced by inadequate salaries to find ways to supplement their incomes, and tutoring provided a way to do it (Silova 2010). In more recent times, economic structures have improved in at least parts of the region, but the culture of tutoring seems now to have become part of the ongoing social fabric. In North America and Western Europe, tutoring has grown as societies have become more competitive, partly because of economic conditions and also under the influence of governments that have devised rankings of schools and have rewarded high achievers (Baker and LeTendre 2005; Ventura 2008b). In Africa, tutoring is emerging as teachers see it as a way to supplement incomes and as parents see it as a way to enhance the opportunities for their children (Bray and Suso 2008). In Latin America, tutoring remains relatively modest except at the upper secondary level. This again reflects traditions in education systems - but traditions could change in Latin America just as they have in other part of the world.

A further established lesson from the field of comparative education is that great care must be taken with terminology (Crossley and Watson 2003, pp. 41-42). In particular, the same word may be used in different settings with different meanings. What is meant by supplementary tutoring in rural Cambodia is very different from what is meant in urban Korea. This is not just a matter of the structures under which pupils and tutors come together; it is also likely to concern the expectations, the quality and the whole orientation of tutoring. Korea has a highly technological society in which tutoring providers are keeping ahead with downloadable lessons that pupils can access on hand-held devices that can be read in the park and on the metro, and which can be fast-forwarded or repeated according to the pupils' wishes (Choe 2009). Korea also has many courses on the internet which in many cases include webcam technology and allow tutees and tutors to talk face-to-face without the barriers of distance.

In some respects, moreover, not only in Korea but also in countries such as France, Canada, and Singapore, tutoring has moved beyond being just a shadow of the regular system to become a system in its own right which offers additional learning opportunities. Thus, some tutoring providers attract clients with promises of advanced and diversified learning of types that go considerably beyond the standard offer of regular schools. As such, the tutoring becomes a supplement rather than just a repeat of the mainstream system. Alongside, some tutoring covers material for regular classes in advance rather than subsequently (Lee et al. 2004; Tan 2009). Thus, while shadow education is a convenient term to cover a broad phenomenon, in many settings it is unsatisfactory because it lacks specificity.

Finally, although an essential part of the definition of shadow education as set out by such authors as Marimuthu et al. (1991), Stevenson and Baker (1992) and Bray (1999a) was its location in the private sector, in some countries the involvement of governments has blurred categories. In the USA, the No Child Left Behind (NCLB) scheme launched in 2002 provided funds through which private tutors could be employed to assist children in low-income families (Burch et al. 2006). The Australian government in 2004 launched a similar Tutorial Voucher Initiative through which parents of low-achieving children could pay for private tutors to help raise learning scores (Watson 2008, p. 8). The Singaporean government provides grants to community bodies such as the Singapore Indian Development Association (SINDA) to provide tutoring for families deemed by the Association to be eligible (Tan 2009, p. 99); and in 2007 the English authorities launched a scheme entitled 'Making Good Progress' through which parents of low achievers could employ private tutors and/or such tutors could be employed by the schools (Pricewaterhouse Coopers 2008). Such initiatives could require reconsideration of the nature of categories to decide what is part of regular educational provision and what is part of the shadow.

\section{Conclusions}

A major theme of this paper, to which reference has been made at various points, concerns the definition of shadow education. The term is attractive and can be meaningful, but may also be ambiguous. As with other fields of enquiry, 
considerable problems can arise when different researchers use the term in different ways, especially when they are not explicit about that fact. The increased volume of research on the topic is much to be welcomed, since it provides a stronger base of evidence on the scale, nature, and implications of shadow education. Returning to the metaphor of the jigsaw puzzle used at the beginning, considerably more pieces are available than was the case in 1999. Many gaps remain, however, both in the geographic coverage and in the specific themes addressed by researchers. Moreover, not all the pieces for the jigsaw puzzle fit together because researchers have based their work on different assumptions and have approached their work with varying degrees of rigour. The field is in need of stronger conceptualisation to take account of the different types of shadow education which have emerged and developed in different settings.

Many of the remarks in this paper are pertinent to all branches of educational studies and to many other domains of enquiry. They concern the design of instruments to collect data, and the constraints on the ability and willingness of some potential respondents to provide data. They also concern the iterations and complementarities of quantitative and qualitative methods of enquiry. They further concern the strengths and weaknesses of comparison at various levels both within and across countries and cultures. Among the very positive signs is that the literature on shadow education has greatly expanded, which means that the phenomenon is gaining considerably greater attention than was previously the case. To some extent this may be because the shadow has itself expanded, but it also reflects clearer recognition of a longstanding phenomenon. The shadow has also taken on new forms as a result of new technologies and other factors.

It seems likely that the shadow will continue to expand and to diversify in most parts of the world. Some observers would consider this beneficial, viewing most or all forms of education as ways to expand versatility and increase human capital in the general population (Dang and Rogers 2008). Other observers would consider developments to be problematic, highlighting issues of social inequalities, pressures on young children, and possible diversion of resources from other potentially more productive uses. These debates also will be enriched by a stronger base of evidence which can be provided by researchers who pay close attention to methodological issues.

\section{References}

Baker, D. P., Akiba, M., LeTendre, G. K., \& Wiseman, A. W. (2001). Worldwide shadow education: Outside-school learning, institutional quality of schooling, and cross-national mathematics achievement. Educational Evaluation and Policy Analysis, 23(1), 1-17.
Baker, D. P., \& LeTendre, G. K. (2005). National differences, global similarities: World culture and the future of schooling. Stanford: Stanford University Press.

Bendall, L., \& Tourte, L. (Reporters) (2009). Le soutien scolaire, réussite ou échec? France 2 channel broadcast, January 22. Retrieved January 312009 from http://envoye-special.france2. fr/index-fr.php?page=reportage-bonus\&id_article $=1205$.

Bray, M. (1996). Counting the full cost: Parental and community financing of education in East Asia. Washington: The World Bank in collaboration with UNICEF.

Bray, M. (1999a). The shadow education system: Private tutoring and its implications for planners. Fundamentals of Educational Planning No.61, Paris: UNESCO International Institute for Educational Planning (IIEP). Available on http://unesdoc.unesco. org/images/0018/001802/180205e.pdf.

Bray, M. (1999b). The private costs of public schooling: household and community financing of primary education in Cambodia. Paris: UNESCO International Institute for Educational Planning (IIEP). Available on http://unesdoc.unesco.org/images/0011/0011 76/117632E.pdf.

Bray, M., Adamson, B., \& Mason, M. (2007). Comparative education research: Approaches and methods. Dordrecht, Hong Kong: Springer, Comparative Education Research Centre, The University of Hong Kong.

Bray, M., \& Suso, E. (2008). The challenges of private supplementary tutoring: global patterns and their implications for Africa. Paper presented at the Biennale of the Association for the Development of Education in Africa (ADEA), Maputo, Mozambique, May 5-9. Available on http://www.adeanet.org/adeaPortal/adea/Biennale\% 202008/Documentation/Papers\%20for\%20presentation/04.\%20 Session\%204/Paralle1\%20session\%204D/Final\%20PDF\% 20 documents/Session\%204D\%20Doc\%201\%20IIEP\%20ENG. pdf.

Buchmann, C. (2002). Getting ahead in Kenya: Social capital, shadow education, and achievement. In B. Fuller \& E. Hannum (Eds.), Schooling and social capital in diverse cultures (pp. 133-159). Amsterdam: JAI Press.

Burch, P., Donovan, J., \& Steinberg, M. (2006). The new landscape of educational privatization in the era of NCLB. Phi Delta Kappan, $88(2), 129-135$.

Choe, S. H. (2009). Online courses: Equalizer for Koreans? International Herald Tribune, June 2, p. 14.

Crossley, M., \& Watson, K. (2003). Comparative and international research in education: Globalisation context and difference. London: RoutledgeFalmer.

Dang, H. A. (2007). The determinants and impact of private tutoring classes in Vietnam. Economics of Education Review, 26(6), 684-699.

Dang, H. A., \& Rogers, H. (2008). How to interpret the growing phenomenon of private tutoring: human capital deepening, inequality increasing, or waste of resources? Policy Research Working Paper 4530. Washington, DC: The World Bank.

Davies, S., \& Aurini, J. (2006). The franchising of private tutoring: A view from Canada. Phi Delta Kappan, 88(2), 123-128.

Dawson, W. (2009). The tricks of the teacher: Shadow education and corruption in Cambodia. In S. P. Heyneman (Ed.), Buying your way into heaven: Education and corruption in international perspective (pp. 51-74). Rotterdam: Sense Publishers.

de Silva, W. A., Gunawardene, C., Jayaweera, S., Perera, L., Rupasinghe, S., \& Wijetunge, S. (1991). Extra-school instruction, social equity and educational quality (Sri Lanka).. Singapore: International Development Research Centre.

Dindyal, J., \& Besoondyal, H. (2007). Private tutoring in mathematics: the Mauritian experience. Paper presented at the conference on redesigning pedagogy: culture, knowledge and understanding. Retrieved August 1, 2009 from http://conference.nie.edu.sg/ 2007/paper/papers/CUL394.pdf. 
Elbadawy, A., Ahlburg, D., Levison, D., \& Assaad, R. (2006). Private and group tutoring in Egypt: Where is the gender inequality? Minneapolis: Department of Economics, University of Minnesota. Retrieved July 30, 2009 from http://iussp2009.princeton. edu/download.aspx? submissionId=91279.

George, C. (1992). Time to come out of the shadows. Straits Times, April 4, p. 28.

Gurun, A., \& Millimet, D. L. (2008). Does private tutoring payoff?. Discussion Paper No.3637, Bonn: Institute for the Study of Labor. Retrieved August 10, 2009 from http://ftp.iza.org/dp3637. pdf.

Hartmann, S. (2008). The informal market of education in Egypt: private tutoring and its implications. Working Papers No.88, Mainz: Institut für Ethnologie und Afrikastudien, Johannes Gutenberg-Universität. Retrieved June 7, 2009 from www.ifeas. uni-mainz.de/workingpapers/AP88.pdf.

Kim, M. (2007). School choice and private supplementary education in South Korea. Paper presented at the IIEP policy forum on confronting the shadow education system: What government policies for what private tutoring? Paris: IIEP-UNESCO.

Kwok, P. (2004). Examination-oriented knowledge and value transformation in East Asian cram schools. Asia Pacific Education Review, 5(1), 64-75.

Lee, J. T., Kim, Y. B., \& Yoon, C. H. (2004). The effects of pre-class tutoring on student achievement: Challenges and implications for public education in Korea. KEDI Journal of Educational Policy, 1(1), 25-42.

Lee, C. J., Park, H. J., \& Lee, H. S. (2009). Shadow education systems. In G. Sykes, B. L. Schneider, \& D. N. Plank (Eds.), Handbook of educational policy research (pp. 901-919). New York: Routledge.

Manzon, M. (2007). Comparing places. In M. Bray, B. Adamson, \& M. Mason (Eds.), Comparative education research: Approaches and methods (pp. 85-121). Dordrecht, Hong Kong: Springer, Comparative Education Research Centre, The University of Hong Kong.

Marimuthu, T., Singh, J. S., Ahmad, K., Lim, H. K., Mukherjee, H., Osman, S., et al. (1991). Extra-school instruction, social equity and educational quality [in Malaysia]. Singapore: International Development Research Centre.

Martin, M.O. (1996). Third International Mathematics and Science Study: an overview'. In M.O. Martin \& D.L. Kelly (eds.), Third International Mathematics and Science Study (TIMSS) technical report, volume I: design and development. (pp. 1-20) Chestnut Hill, MA: TIMSS International Study Center, Boston College. Retrieved August 10, 2009 from http://timss.bc.edu/timss1995i/ TIMSSPDF/TRCHP1.PDF

Mason, M. (2007). Comparing cultures. In M. Bray, B. Adamson, \& M. Mason (Eds.), Comparative education research: Approaches and methods (pp. 165-196). Dordrecht, Hong Kong: Springer, Comparative Education Research Centre, The University of Hong Kong.

Megahed, N. M., \& Ginsburg, M. B. (2003). Stratified students, stratified teachers: Ideologically informed perceptions of educational reform in Egypt. Mediterranean Journal of Educational Studies, 8(2), 7-33.

Mischo, C., \& Haag, L. (2002). Expansion and effectiveness of private tutoring. European Journal of Psychology of Education, XVII(3), 263-273.

Mulji, N. (2003). All work and no play. The Review [weekly magazine supplement for Dawn newspaper, Pakistan], August 28-September 3, pp.4-8.

Mullis, I. V. S., \& Martin, M. O. (2008). Overview of TIMSS 2007. In TIMSS 2007 technical report. (pp.1-12). Boston: TIMSS and PIRLS International Study Center, Lynch School of Education, Boston College.
Mullis, I. V. S., Martin, M. O., \& Foy, P. (2005). IEA's TIMSS 2003 international report on achievement in the mathematics cognitive domains: Findings from a developmental project. Boston: TIMSS and PIRLS International Study Center, Lynch School of Education, Boston College.

Ng, Y. H. (2009). Tutors are like actors. Deccan Herald, June 4. Retrieved August 3, 2009 from http://www.deccanherald.com/ content/8619/tutors-like-actors.html.

Noah, H. J., \& Eckstein, M. A. (1998). Doing comparative education: Three decades of collaboration. Hong Kong: Comparative Education Research Centre, The University of Hong Kong.

Organisation for Economic Co-operation and Development (OECD) (2005a). Parent questionnaire for PISA 2006: main study. Paris: OECD. Retrieved August 10, 2009 from http://pisa2006.acer. edu.au/downloads/PISA06_Parent_questionnaire.pdf.

Organisation for Economic Co-operation and Development (OECD) (2005b). Student questionnaire for PISA 2006: main study. Paris: OECD. Retrieved August 10, 2009 from http://pisa2006.acer. edu.au/downloads/PISA06_Student_questionnaire.pdf.

Paviot, L., Heinsohn, N., \& Korkman, J. (2008). Extra tuition in southern and eastern Africa: coverage, growth and linkages with pupil achievement. International Journal of Educational Development, 28(2), 149-160.

Peters, M., Carpenter, H., Edwards, G., \& Coleman, N. (2009). Private tuition: survey of parents and carers. Research brief DCSF-RBX-09-01. London: Department for Schools and Families. Retrieved August 5, 2009 from http://www.dcsf.gov.uk/ research/programmeofresearch/projectinformation.cfm?project id $=15666$ \& resultspage $=1$.

Popa, S., \& Acedo, C. (2006). Redefining professionalism: Romanian secondary education teachers and the private tutoring system. International Journal of Educational Development, 26(1), 98-110.

Pricewaterhouse Coopers (2008). Evaluation of the making good progress pilot: interim report. Research report SCSF-RR065. London: Department for Children, Schools and Families. Retrieved August 4, 2009 from http://publications.dcsf.gov.uk/default.aspx? PageFunction=productdetails $\&$ PageMode=publications \& Product Id=DCSF-RR065.

Rao, N., \& Chan, C. K. K. (2009). Moving beyond paradoxes: Understanding Chinese learners and their teachers. In C. K. K. Chan \& N. Rao (Eds.), Revisiting the Chinese learner: Changing contexts, changing education (pp. 3-32). Dordrecht, Hong Kong: Springer, Comparative Education Research Centre, The University of Hong Kong.

Refsing, K. (1992). Japanese educational expansion: Quality or equality. In R. Goodman \& K. Refsing (Eds.), Ideology and practice in modern Japan (pp. 116-119). London: Routledge.

Robitaille, D. F., \& Beaton, A. E. (2002). TIMSS: A brief overview of the study. In D. F. Robitaille \& A. E. Beaton (Eds.), Secondary analysis of the TIMSS data (pp. 11-18). Dordrecht: Kluwer Academic Publishers.

Roesgaard, M. H. (2006). Japanese education and the cram school business: Functions, challenges and perspectives of the juku. Copenhagen: NIAS [Nordic Institute of Asian Studies] Press.

Rohlen, T. P., \& LeTendre, G. K. (1996). Conclusion: Themes in the Japanese culture of learning. In T. P. Rohlen \& G. K. LeTendre (Eds.), Teaching and learning in Japan (pp. 369-376). Cambridge: Cambridge University Press.

Salili, F. (2005). Accepting personal responsibility for learning. In D. A. Watkins \& J. B. Biggs (Eds.), Chinese learner: Cultural, psychological and contextual influences (pp. 85-105). Hong Kong: Comparative Education Research Centre, The University of Hong Kong.

Silova, I. (2009). Private supplementary tutoring in central Asia: New opportunities and burdens. Paris: UNESCO International Institute for Educational Planning (IIEP). 
Silova, I. (2010). Private tutoring in eastern Europe and central Asia: Policy choices and implications. Compare: A Journal of International and Comparative Education, 40(2).

Silova, I., Būdienè, V., \& Zabulionis, A. (2006). Methodological considerations. In I. Silova, V. Būdienè, \& M. Bray (Eds.), Education in a hidden market place: Monitoring of private tutoring (pp. 61-69). New York: Open Society Institute.

Smith, I. D. (2003). Homework and coaching. In J. P. Keeves \& R. Watanabe (Eds.), International handbook of educational research in the Asia-Pacific region (pp. 755-766). Dordrecht: Kluwer.

Smyth, E. (2009). Buying your way into college? Private tuition and the transition to higher education in Ireland. Oxford Review of Education, 35(1), 1-22.

Stevenson, D. L., \& Baker, D. P. (1992). Shadow education and allocation in formal schooling: Transition to university in Japan. American Journal of Sociology, 97(6), 1639-1657.

Tan, J. (2009). Private tutoring in Singapore: Bursting out of the shadows. Journal of Youth Studies [Hong Kong], 12(1), 93-103.

Tanner, E., Day, N., Tennant, R., Turczuk, O., Ireson, J., Rushforth, K., \& Smith, K. (2009). Private tuition in England. Research report DCSF-RR081. London: Department for Schools and Families. Retrieved August 5, 2009 from http://www.dcsf.gov. uk/research/data/uploadfiles/DCSF-RR081.pdf.

TIMSS (Third International Mathematics and Science Study) (1998). International version of the background questionnaires
Population 2. Chestnut Hill, MA: TIMSS International Study Center, Boston College. Retrieved August 10, 2009 from http:// timss.bc.edu/timss1995i/database/UG1_Sup2.pdf.

TIMSS (Trends in International Mathematics and Science Study) (2003). TIMSS 2003 student questionnaire Grade 8. Chestnut Hill, MA: TIMSS International Study Center, Boston College. Retrieved August 10, 2009 from http://timss.bc.edu/timss2003i/ PDF/T03_StudentS_8.pdf.

Ventura, A. (2008a). Explicações através da Internet: globalização e offshoring. In J. A. Costa, A. Neto-Mendes, \& A. Ventura (Eds.), Xplika: Investigação sobre o mercado das explicações (pp. 69-84). Aveiro: Universidade de Aveiro.

Ventura, A. (2008b). Private supplementary tutoring in Europe: An overview. Paper presented at the 9th International Conference on Educational Research, Seoul National University, October 27-28.

Watson, L. (2008). Private expectations and public schooling: The growth of private tutoring in Australia. Paper presented at the national conference of the Australian Association for Research in Education (AARE), November 30-December 4. Retrieved August 5, 2009 from http://ocs.sfu.ca/aare/index.php/AARE_ 2008/AARE/paper/viewFile/692/170.

Wolf, R. M. (2002). Extra-school instruction in mathematics and science. In D. F. Robitaille \& A. E. Beaton (Eds.), Secondary analysis of the TIMSS data (pp. 331-341). Dordrecht: Kluwer Academic Publishers. 